\title{
Diagnosis and Treatment of Anaplastic Thyroid Carcinoma
}

\author{
Patorn Piromchai, Teeraporn Ratanaanekchai, Pornthep Kasemsiri \\ Department of Otorhinolaryngology, Faculty of Medicine, Khon Kaen University, Khon Kaen, Thailand. \\ Email: patorn@gmail.com
}

Received October $7^{\text {th }}, 2011$; revised November $16^{\text {th }}, 2011$; accepted December $14^{\text {th }}, 2011$

\begin{abstract}
Anaplastic thyroid carcinoma (ATC) is a poorly differentiated thyroid cancer. It cannot uptake iodine or synthesis thyroglobulin. The incidence is low; about $2 \%-5 \%$ of thyroid cancer. The peak age incidence is $60-70$ years and it is more common in females (55\% - 77\% of all patients). In recent years, the incidence has declined; however, it may be higher in areas of endemic goiter. ATC may occur with a coexisting carcinoma and may represent transformation of a well-differentiated thyroid cancer. Patients typically present with a rapidly growing anterior neck mass and aggressive symptoms. The most reliable tool in detecting thyroid malignancies is fine-needle aspiration cytology (FNAC). Sensitivity of FNAC for thyroid malignancy ranged from $61 \%$ to $97.7 \%$. Fine-needle aspiration can diagnose ATC by the demonstration of spindled or giant cells, bizarre neoplastic cells that may be multinucleated, or atypical cells with high mitotic activity. A syncytial pattern is the predominant cellular pattern of anaplastic thyroid carcinoma. Other laboratory tests, including tumor markers (cytokeratin, vimentin, and carcinoembryogenic antigen) are helpful in diagnosis and follow-up of the patients. Multimodality therapy (surgery, external beam radiation, and chemotherapy) is the recommended treatment and it seems to have slightly improved outcomes. The prognosis is not as bad in younger patients with smaller tumors. The most common cause of death is lung metastasis. The mean survival time is less than 6 months from the time of diagnosis. The prompt diagnosis and aggressive treatment are essential modality to achieve optimal outcomes.
\end{abstract}

Keywords: Anaplastic Thyroid Carcinoma; Thyroid; Cancer

\section{Introduction}

Anaplastic thyroid carcinoma (ATC) is a poorly differentiated thyroid cancer. It cannot uptake iodine or synthesis thyroglobulin. The incidence is low; about $2 \%-5 \%$ of thyroid cancer. The peak age incidence is 60 - 70 years and it is more common in females $(55 \%-77 \%$ of all patients). In recent years, the incidence has declined; however, it may be higher in areas of endemic goiter. ATC may occur with a coexisting carcinoma and may represent transformation of a well-differentiated thyroid cancer (WDTC). In Mumbai, the incidence decreased from 7.7\% to $4.2 \%$ between 1969-1973 and 1989-1993 [1]. A study from Italy also showed a decrease from $11 \%$ to $5 \%$ between 1979 to 1989 [2]. This decline may be caused by the improvement of immunochemistry technique that can exclude lymphomas or undifferentiated medullary thyroid carcinoma from previously diagnosed ATC patients [3-6] and the aggressive surgical resection of WDTC has reduced the risk of anaplastic transformation (dedifferentiation) of WDTC to ATC [7].

Patients typically present with a rapidly growing ante- rior neck mass and aggressive symptoms such as hoarseness, dysphagia, upper airway obstruction, pulmonary metastases, and superior vena cava obstruction. The most common cause of death is pulmonary metastases and mean survival time is less than 6 months from the time of diagnosis [8]. In this article, we review on diagnosis and treatment of ATC.

\section{Diagnosis}

The most common presenting symptom of anaplastic thyroid carcinoma (ATC) is a rapidly enlarging fixed, hard neck mass, often with a lateral cervical mass (metastatic lymph node) [9-12]. The mass effect of the tumor usually produces symptoms of hoarseness (77\%), dysphagia (56\%), vocal cord paralysis (49\%), neck pain (29\%), weight loss (24\%), dyspnea (19\%), and stridor [13]. A single nodule may be present in $58 \%$ of patients, multiple nodules in $36 \%$, bilateral involvement in $24 \%$, and a diffuse hard, fixed lesion in 75\% [13]. Lymph node metastases and extrathyroidal extension in the absence of distant metastases are present in $53 \%$ to $64 \%$ of patients. 
Distant metastases are present in a one quarter to twothirds of patients. The most common site are the mediastinum and lungs (42\%), followed by bone (32\%) and brain (9\%) [14].

Microscopically, the tumours are composed of anaplastic cells with marked cytologic atypia and high mitotic activity. The morphologic criteria employed to define poorly differentiated thyroid carcinoma in most publications have been trabecular, solid, insular, cribriform and scirrhous growth patterns [15-17]. The pathogenesis of ATC remains undefined. The most widely accepted theory is that ATC develops from pre-existing differentiated thyroid cancer of papillary or follicular type. Because of the infrequency of the tumor, it is rarely possible to study sufficient numbers of patients to obtain a better understanding of the natural history and the factors that may influence treatment and survival. Dedifferentiation manifested by a loss of specific thyroid cell characteristics and functions, including expression of thyroglobulin, thyroid peroxidase, thyroid-stimulating hormone receptor, and sodium/iodide symporter expression is a hallmark of ATC. Consequently, thyroglobulin can not be used as a tumor marker for diagnosis or monitoring. Cytokeratin is a useful epithelial immunohistochemical marker and present in $40 \%$ to $100 \%$ of tumors $[13,18]$. Other markers suggesting epithelial origin of the tumor may be epithetlial membrane antigen, and carcinoembryonic antigen [13]. Vimentin is another helpful immunohistochemical marker $[8,18]$.

Fine-needle aspiration cytology (FNAC) is the most reliable tool in detecting thyroid malignancies. FNAC should be performed in any thyroid nodule $>1 \mathrm{~cm}$ and in those $<1 \mathrm{~cm}$ if there is any clinical (history of head and neck irradiation, family history of thyroid cancer, suspicious features on palpation, presence of cervical adenopathy) or ultrasonographic suspicion of malignancy [19]. Sensitivity of FNAC for thyroid malignancy ranges from $61 \%$ to $97.7 \%$ [20-23]. Fine-needle aspiration can diagnose ATC by the demonstration of spindled or giant cells, bizarre neoplastic cells that may be multinucleated, or atypical cells with high mitotic activity. Syncytial pattern (sheets of follicular cells with loss of polarity and lack of distinct cell borders) is the predominant cellular pattern of anaplastic thyroid carcinoma [24].

It has been proposed that fine needle capillary sampling (FNC) was better than FNA by reducing trauma to cells and tissues, resulting in less pain, less haemorrhage and specimens of higher quality [25]. In a meta-analysis, no method was found superior to the other [26]. Complications of FNAC included pain/discomfort, haemorrhage/ haematomas, recurrent laryngeal nerve palsy, vasovagal reactions, needle track seeding, nodule volume alterations, and post-aspiration thyrotoxicosis [27]. Needle track seeding was a rare complication. Only one study has reported needle track seeding in anaplastic thyroid carcinoma [28]. Tumor cells released into the surrounding tissues or circulation are probably destroyed by the host immune response or other mechanisms before giving rise to clinically apparent [27].

Ultrasound scans provide information about the location and nature (cystic vs non-cystic) of the tumor. The sensitivity of ultrasound in evaluating thyroid nodules for malignancy ranges from $41.4 \%$ to $86.5 \%$ [23,29,30]. Ultrasound-guided FNAC should be carried out in tumors located posteriorly or those with more than 50\% cystic content, which are poorly evaluated with palpation-guided FNAC [31]. Computed Tomography (CT) and Magnetic Resonance Imaging (MRI) are necessary in some cases to determine the staging and extent of the disease, and in planning surgery [32]. 18F-fluorodeoxygluconate positron emission tomography (18F-FDG PET) is useful in the early evaluation of treatment response and follow-up [33,34].

Frozen section should be considered unnecessary because it does not affect the intraoperative decision making [35]. The sensitivity of frozen section ranges widely from $32.4 \%$ to $93 \%$ [23,36-39]. Frozen sections distort and collapse the blood vessels of the thyroid gland, increaseing the difficulty in detecting angioinvasion which is an important feature in differentiating between follicular adenomas and carcinomas [40].

\section{Treatment}

Multimodality treatment is the recommended treatment although it seems to have only slightly improved outcomes. It consists of surgery, external beam radiation and chemotherapy. Besides tumor resection, tracheostomy may be indicated for advanced disease. Surgery has an important role in ATC, especially when complete removal can be achieved. However, the extent of the resection must be carefully weighed against its morbidity, given the poor prognosis of the disease. Although tracheal resection may be performed in selected cases, resections of the larynx, pharynx, and esophagus are generally discouraged $[8,41,42]$. Furthermore, some studies found that neither the extent of the operation nor the completeness of the tumor resection affected survival[14]. Because of its aggressive nature, complete surgical resection is recommended whenever possible if excessive morbidity can be avoided $[8,43]$.

Lateral neck dissections should be performed if neck nodes are palpable and resectable. Although postoperative external beam irradiation or adjunctive chemotherapy adds little to the overall prognosis [44], some studies found that it may prevent death from local airway obstruction and at best may slightly prolong survival [8, $13,14,45]$. 
Doxorubicin has become established as a standard chemotherapy [46-52], often in combination with cisplatin $[51,53]$. Tracheostomy may be the initial management for patients with impending airway obstruction and may be the single treatment for patients who are not candidates for local resection or chemoradiation [8,54]. Prophylactic tracheostomy in the absence of impending risk to the airway is discouraged [11].

Mclver [14] found that the median survival was 3.5 months in patients undergoing surgery versus 2.3 months in patients receiving radiotherapy, but only 3 weeks if palliative care was provided. Smallridge reviewed 35 studies including 1771 patients treated between 1949 and 2007. He found that the median survival of all series was only 5 months and the median 1-year survival was $20 \%$ [55]. Several investigators concluded that younger patients [41,56-58] and smaller tumor size carried a better prognosis $[3,57,59]$. The most common causes of death are lung metastasis (35\%), airway obstruction (16\%), and tumor-related heamorrhage (14\%). The tumor sites mainly responsible for death included concomitant local and distant metastases (40\%), local disease (34\%), and distant metastases (24\%) [54].

\section{Conclusion}

Anaplastic thyroid cancer (ATC) is a rare malignancy which behaves aggressively. Currently, FNAC is useful for diagnosis and tumor markers (cytokeratin, vimentin, and carcinoembryogenic antigen) help in diagnosis and follow-up of the patients. The treatment of choice is surgery with radiotherapy and chemotherapy. Complete surgical resection is desirable in ATC, but most patients present with inoperable tumor and thus palliative care and other modalities should be considered in these circumstances. Prompt diagnosis and aggressive treatment are the essential if there is to be any hope of curing this disease.

\section{Acknowledgements}

We appreciate the assistance received from Prof Robert Peter Mills and Dr Piyawadee Lertchanaruengrith in the editing of the manuscript.

\section{REFERENCES}

[1] S. Agrawal, R. S. Rao, D. M. Parikh, H. K. Parikh, A. M. Borges and M. B. Sampat, "Histologic Trends in Thyroid Cancer 1969-1993: A Clinico-Pathologic Analysis of the Relative Proportion of Anaplastic Carcinoma of the Thyroid,” Journal of Surgical Oncology, Vol. 63, No. 4, 1996, pp. 251-255.

doi:10.1002/(SICI)1096-9098(199612)63:4<251::AID-JS O7>3.0.CO;2-B

[2] P. Lampertico, “Anaplastic (Sarcomatoid) Carcinoma of the Thyroid Gland," Seminars in Diagnostic Pathology, Vol. 10, No. 2, 1993, pp. 159-168.

[3] R. K. Tan, R. K. Finley III, D. Driscoll, V. Bakamjian, W. L. Hicks Jr. and D. P. Shedd, "Anaplastic Carcinoma of the Thyroid: A 24-Year Experience,” Head \& Neck, Vol. 17, No. 1, 1995, pp. 41-48. doi:10.1002/hed.2880170109

[4] M. W. Myskow, A. S. Krajewski, A. E. Dewar, E. P. Millar, K. McLaren and J. W. Fabre, "The Role of Immunoperoxidase Techniques on Paraffin Embedded Tissue in Determining the Histogenesis of Undifferentiated Thyroid Neoplasms,” Clinocal Endocrinology, Vol. 24, No. 3, 1986, pp. 335-341. doi:10.1111/j.1365-2265.1986.tb03275.x

[5] A. Tobler, R. Maurer and C. E. Hedinger, "Undifferentiated Thyroid Tumors of Diffuse Small Cell Type. Histological and Immunohistochemical Evidence for Their Lymphomatous Nature,” Virchows Archiv, Vol. 404, No. 2, 1984, pp. 117-126. doi:10.1007/BF00704057

[6] T. Holting, P. Moller, C. Tschahargane, H. Meybier, H. Buhr and C. Herfarth, "Immunohistochemical Reclassification of Anaplastic Carcinoma Reveals Small and Giant cell Lymphoma,” World Journal of Surgery, Vol. 14, No. 3, 1990, pp. 291-295. doi:10.1007/BF01658506

[7] J. G. Demeter, S. A. De Jong, A. M. Lawrence and E. Paloyan, "Anaplastic Thyroid Carcinoma: Risk Factors and Outcome,” Surgery, Vol. 110, No. 3, 1991, pp. 956-961.

[8] C. Are and A. R. Shaha, “Anaplastic Thyroid Carcinoma: Biology, Pathogenesis, Prognostic Factors, and Treatment Approaches,” Annals of Surgical Oncology, Vol. 13, No. 4, 2006, pp. 453-464. doi:10.1245/ASO.2006.05.042

[9] S. M. Wiseman, H. Masoudi, P. Niblock, D. Turbin, A. Rajput, J. Hay, S. Bugis, D. Filipenko, D. Huntsman and B. Gilks, “Anaplastic Thyroid Carcinoma: Expression Profile of Targets for Therapy Offers New Insights for Disease Treatment," Annals of Surgical Oncology, Vol. 14, No. 2, 2007, pp. 719-729. doi:10.1245/s10434-006-9178-6

[10] H. S. Chang, K. H. Nam, W. Y. Chung and C. S. Park, "Anaplastic Thyroid Carcinoma: A Therapeutic Dilemma,” Yonsei Medical Journal, Vol. 46, No. 6, 2005, pp. 759-764. doi:10.3349/ymj.2005.46.6.759

[11] K. B. Ain, “Anaplastic Thyroid Carcinoma: A Therapeutic Challenge," Seminars in Surgical Oncology, Vol. 16, No. 1, 1999, pp. 64-69.

doi:10.1002/(SICI)1098-2388(199901/02)16:1<64::AIDSSU10>3.0.CO;2-U

[12] J. Shvero, R. Gal, I. Avidor, T. Hadar and E. Kessler, “Anaplastic Thyroid Carcinoma. A Clinical, Histologic, and Immunohistochemical Study,” Cancer, Vol. 62, No. 21, 1988, pp. 319-325.

doi:10.1002/1097-0142(19880715)62:2<319::AID-CNCR 2820620216>3.0.CO;2-T

[13] D. Giuffrida and H. Gharib, "Anaplastic Thyroid Carcinoma: Current Diagnosis and Treatment," Annals of Oncology, Vol. 11, No. 9, 2000, pp. 1083-1089. doi:10.1023/A:1008322002520

[14] B. McIver, I. D. Hay, D. F. Giuffrida, C. E. Dvorak, C. S. Grant, G. B. Thompson, J. A. van Heerden and J. R. Goellner, "Anaplastic Thyroid Carcinoma: A 50-Year Experience at a Single Institution,” Surgery, Vol. 130, No. 6, 
2001, pp. 1028-1034. doi:10.1067/msy.2001.118266

[15] H. L. Evans, "Columnar-Cell Carcinoma of the Thyroid. A Report of Two Cases of an Aggressive Variant of Thyroid Carcinoma,” American Journal of Clinical Pathology, Vol. 85, No. 1, 1986, pp. 77-80.

[16] M. Sobrinho-Simoes, J. M. Nesland and J. V. Johannessen, "Columnar-Cell Carcinoma. Another Variant of Poorly Differentiated Carcinoma of the Thyroid," American Journal of Clinical Pathology, Vol. 89, No. 2, 1988, pp. 264267.

[17] M. Papotti, F. Botto Micca, A. Favero, N. Palestini and G. Bussolati, "Poorly Differentiated Thyroid Carcinomas with Primordial Cell Component. A Group of Aggressive Lesions Sharing Insular, Trabecular, and Solid Patterns,” American Journal of Surgical Pathology, Vol. 17, No. 3, 1993, pp. 291-301. doi:10.1097/00000478-199303000-00010

[18] N. G. Ordonez, A. K. El-Naggar, R. C. Hickey and N. A. Samaan, "Anaplastic Thyroid Carcinoma. Immunocytochemical Study of 32 Cases,” American Journal of Clinical Pathology, Vol. 96, 1991, pp. 15-24.

[19] F. Pacini, M. G. Castagna, L. Brilli and G. Pentheroudakis, "Thyroid Cancer: ESMO Clinical Practice Guidelines for Diagnosis, Treatment and Follow-Up,” Annals of Oncology, Vol. 21, Supplement 5, 2010, pp. 214-219. doi:10.1093/annonc/mdq190

[20] G. L. La Rosa, A. Belfiore, D. Giuffrida, C. Sicurella, O. Ippolito, G. Russo and R. Vigneri, "Evaluation of the Fine Needle Aspiration Biopsy in the Preoperative Selection of Cold Thyroid Nodules,” Cancer, Vol. 67, No. 8, 1991, pp. 2137-2141. doi:10.1002/1097-0142(19910415)67:8<2137::AID-CNC R2820670822>3.0.CO;2-Y

[21] D. C. Howlett, B. Harper, M. Quante, A. Berresford, M. Morley, J. Grant, K. Ramesar and S. Barnes, "Diagnostic Adequacy and Accuracy of Fine Needle Aspiration Cytology in Neck Lump Assessment: Results from a Regional Cancer Network over a One Year Period,” The Journal of Laryngology \& Otology, Vol. 121, No. 6, 2007, pp. 571-579. doi:10.1017/S0022215106004944

[22] Y. Bajaj, M. De and A. Thompson, "Fine Needle Aspiration Cytology in Diagnosis and Management of Thyroid Disease," The Journal of Laryngology \& Otology, Vol. 120, No. 6, 2006, pp. 467-469. doi:10.1017/S0022215106000703

[23] W. J. Tan, K. Sanghvi, K. H. Liau and C. H. Low, “An Audit Study of the Sensitivity and Specificity of Ultrasound, Fine Needle Aspiration Cytology and Frozen Section in the Evaluation of Thyroid Malignancies in a Tertiary Institution," Annals of the Academy of Medical Singapore, Vol. 39, No. 5, 2010, pp. 359-362.

[24] B. P. Bommanahalli, R. V. Bhat and R. Rupanarayan, “A Cell Pattern Approach to Interpretation of Fine Needle Aspiration Cytology of Thyroid Lesions: A Cyto-Histomorphological Study,” Journal of Cytology, Vol. 27, No. 4, 2010, pp. 127-132. doi:10.4103/0970-9371.73295

[25] A. Yucel, O. Yilmaz, S. Babaoglu, M. Acar and B. Degirmenci, "Sonographic Findings of the Median Nerve and Prevalence of Carpal Tunnel Syndrome in Patients with
Parkinson's Disease,” European Journal of Radiology, Vol. 67, No. 3, 2008, pp. 546-550.

doi:10.1016/j.ejrad.2007.08.001

[26] D. D. Pothier and A. A. Narula, "Should We Apply Suction during Fine Needle Cytology of Thyroid Lesions? A Systematic Review and Meta-Analysis,” Annals of Royal College of Surgions of England, Vol. 88, No. 7, 2006, pp. 643-645. doi:10.1308/003588406X149147

[27] S. A. Polyzos and A. D. Anastasilakis, "Clinical Complications Following Thyroid Fine-Needle Biopsy: A Systematic Review," Clinical Endocrinology, Vol. 71, No. 2, 2009, pp. 157-165. doi:10.1111/j.1365-2265.2009.03522.x

[28] E. Abelardo, M. Jaramillo, E. Sheffield and P. Tierney "Anaplastic Thyroid Carcinoma Implantation after Fine Needle Aspiration Cytology," The Journal of Laryngology \& Otology, Vol. 121, No. 3, 2007, pp. 268-270. doi:10.1017/S0022215106003264

[29] F. Stacul, M. Bertolotto, F. De Gobbis, L. Calderan, V. Cioffi, A. Romano, F. Zanconati and M. A. Cova, "US, Colour-Doppler US and Fine-Needle Aspiration Biopsy in the Diagnosis of Thyroid Nodules," Radiologia Medica, Vol. 112, No. 5, 2007, pp. 751-762. doi:10.1007/s11547-007-0178-9

[30] E. Koike, S. Noguchi, H. Yamashita, T. Murakami, A. Ohshima and H. Kawamoto, "Ultrasonographic Characteristics of Thyroid Nodules: Prediction of Malignancy," Archives of Surgery, Vol. 136, No. 3, 2001, pp. 334-337. doi:10.1001/archsurg.136.3.334

[31] D. S. Cooper, G. M. Doherty, B. R. Haugen, R. T. Kloos, S. L. Lee, S. J. Mandel, E. L. Mazzaferri, B. McIver, S. I. Sherman and R. M. Tuttle, "Management Guidelines for Patients with Thyroid Nodules and Differentiated Thyroid Cancer,” Thyroid, Vol. 16, No. 2, 2006, pp. 109-142. doi:10.1089/thy.2006.16.109

[32] C. Y. Eng, M. S. Quraishi and P. J. Bradley, "Management of Thyroid Nodules in Adult Patients," Head \& Neck Oncology, Vol. 2, 2010, p. 11. doi:10.1186/1758-3284-2-11

[33] T. Poisson, D. Deandreis, S. Leboulleux, F. Bidault, G. Bonniaud, S. Baillot, A. Auperin, A. Al Ghuzlan, J. P. Travagli and J. Lumbroso, et al., "18F-Fluorodeoxyglucose Positron Emission Tomography and Computed Tomography in Anaplastic Thyroid Cancer," European Journal of Nuclear Medicine and Molecular Imaging, Vol. 37, No. 12, 2010, pp. 2277-2285. doi:10.1007/s00259-010-1570-6

[34] N. Khan, N. Oriuchi, T. Higuchi and K. Endo, "Review of Fluorine-18-2-fluoro-2-deoxy-D-glucose Positron Emission Tomography (FDG-PET) in the Follow-Up of Medullary and Anaplastic Thyroid Carcinomas," Cancer Control, Vol. 12, 2005, pp. 254-260.

[35] F. Lumachi, S. Borsato, A. Tregnaghi, F. Marino, F. Polistina, S. M. Basso, H. Koussis, U. Basso and A. Fassina, "FNA Cytology and Frozen Section Examination in Patients with Follicular Lesions of the Thyroid Gland," Anticancer Research, Vol. 29, No. 12, 2009, pp. 5255-5257.

[36] G. F. Huber, P. Dziegielewski, T. W. Matthews, S. J. WarshawskiJ, L. M. Kmet, P. Faris, M. Khalil and J. C. Dort, "Intraoperative Frozen-Section Analysis for Thyroid No- 
dules: A Step toward Clarity or Confusion?” Archives of Otolaryngology Head \& Neck Surgery, Vol. 133, No. 9, 2007, pp. 874-881. doi:10.1001/archotol.133.9.874

[37] M. L. Richards, R. Chisholm, J. M. Bruder and W. E. Strodel, "Is Thyroid Frozen Section Too Much for Too Little?” The American Journal of Surgery, Vol. 184, No. 6, 2002, pp. 510-514. doi:10.1016/S0002-9610(02)01074-7

[38] L. A. Boyd, R. C. Earnhardt, J. T. Dunn, H. F. Frierson and J. B. Hanks, "Preoperative Evaluation and Predictive Value of Fine-Needle Aspiration and Frozen Section of Thyroid Nodules," Journal of the American College of Surgeons, Vol. 187, No. 5, 1998, pp. 494-502. doi:10.1016/S1072-7515(98)00221-X

[39] C. R. McHenry, C. Raeburn, T. Strickland and J. J. Marty, "The Utility of Routine Frozen Section Examination for Intraoperative Diagnosis of Thyroid Cancer," The American Journal of Surgery, Vol. 172, No. 6, 1996, pp. 658661. doi:10.1016/S0002-9610(96)00302-9

[40] R. C. Anton and T. M. Wheeler, "Frozen Section of Thyroid and Parathyroid Specimens," Archives of Pathology \& Laboratory Medicine, Vol. 129, No. 12, 2005, pp. 15751584.

[41] Y. S. Venkatesh, N. G. Ordonez, P. N. Schultz, R. C. Hickey, H. Goepfert and N. A. Samaan, "Anaplastic Carcinoma of the Thyroid. A Clinicopathologic Study of 121 Cases," Cancer, Vol. 66, No. 2, 1990, pp. 321-330. doi:10.1002/1097-0142(19900715)66:2<321::AID-CNCR 2820660221>3.0.CO;2-A

[42] P. I. Haigh, “Anaplastic Thyroid Carcinoma,” Current Treatment Options in Oncology, Vol. 1, No. 4, 2000, pp. 353-357. doi:10.1007/s11864-000-0051-8

[43] L. D. Green, L. Mack and J. L. Pasieka, “Anaplastic Thyroid Cancer and Primary Thyroid Lymphoma: A Review of These Rare Thyroid Malignancies," Journal of Surgical Oncology, Vol. 94, No. 8, 2006, pp. 725-736. doi:10.1002/jso.20691

[44] J. L. Pasieka, “Anaplastic Thyroid Cancer,” Current Treatment Options in Oncology, Vol. 15, No. 1, 2003, pp. 78-83. doi:10.1097/00001622-200301000-00012

[45] D. E. Heron, S. Karimpour and P. W. Grigsby, “Anaplastic Thyroid Carcinoma: Comparison of Conventional Radiotherapy and Hyperfractionation Chemoradiotherapy in Two Groups," American Journal of Clinical Oncology, Vol. 25, No. 5, 2002, pp. 442-446. doi:10.1097/00000421-200210000-00003

[46] S. Prendiville, K. D. Burman, M. D. Ringel, B. M. Shmookler, Z. E. Deeb, K. Wolfe, N. Azumi, L. Wartofsky and R. B. Sessions, "Tall Cell Variant: An Aggressive Form of Papillary Thyroid Carcinoma," Otolaryngology Head and Neck Surgery, Vol. 122, No. 3, 2000, pp. 352357. doi:10.1016/S0194-5998(00)70047-7

[47] G. Crile Jr., K. I. Pontius and W. A. Hawk, "Factors Influencing the Survival of Patients with Follicular Carcinoma of the Thyroid Gland," Surgery, Gynecology \& Obstetrics, Vol. 160, No. 5, 1985, pp. 409-413.

[48] L. Souhami, W. J. Simpson and J. S. Carruthers, "Malig- nant Lymphoma of the Thyroid Gland," International Journal of Radiation Oncology, Vol. 6, No. 9, 1980, pp. 1143-1147. doi:10.1016/0360-3016(80)90166-2

[49] J. S. Burke, J. J. Butler and L. M. Fuller, "Malignant Lymphomas of the Thyroid: A Clinical Pathologic Study of 35 Patients Including Ultrastructural Observations,” Cancer, Vol. 39, No. 4, 1977, pp. 1587-1602. doi:10.1002/1097-0142(197704)39:4<1587::AID-CNCR2 820390434>3.0.CO;2-V

[50] J. Hamburger, "Nontoxic Goiter,” Springfield, Illinois, 1973.

[51] L. E. Holm, H. Blomgren and T. Lowhagen, "Cancer Risks in Patients with Chronic Lymphocytic Thyroiditis," The New England Journal of Medicine, Vol. 312, No. 10, 1985, pp. 601-604. doi:10.1056/NEJM198503073121001

[52] E. D. Williams, "Malignant Lymphoma of the Thyroid," Clinics in Endocrinology and Metabolism, Vol. 10, No. 2, 1981, pp. 379-389. doi:10.1016/S0300-595X(81)80029-1

[53] R. G. Watson, M. D. Brennan, J. R. Goellner, J. A. van Heerden, W. M. McConahey and W. F. Taylor, "Invasive Hurthle Cell Carcinoma of the Thyroid: Natural History and Management,” Mayo Clinic Proceedings, Vol. 59, No. 12, 1984, pp. 851-855.

[54] Y. Kitamura, K. Shimizu, M. Nagahama, K. Sugino, O. Ozaki, T. Mimura, K. Ito and S. Tanaka, "Immediate Causes of Death in Thyroid Carcinoma: Clinicopathological Analysis of 161 Fatal Cases," Journal of Clinical Endocrinology \& Metabolism, Vol. 84, No. 11, 1999, pp. 40434049. doi:10.1210/jc.84.11.4043

[55] R. C. Smallridge and J. A. Copland, "Anaplastic Thyroid Carcinoma: Pathogenesis and Emerging Therapies," Clinical Oncology, Vol. 22, No. 6, 2010, pp. 486-497. doi:10.1016/j.clon.2010.03.013

[56] T. Yau, C. Y. Lo, R. J. Epstein, A. K. Lam, K. Y. Wan and B. H. Lang, "Treatment Outcomes in Anaplastic Thyroid Carcinoma: Survival Improvement in Young Patients with Localized Disease Treated by Combination of Surgery and Radiotherapy," Annals of Surgical Oncology, Vol. 15, No. 9, 2008, pp. 2500-2505.

doi:10.1245/s10434-008-0005-0

[57] J. P Pierie, A. Muzikansky, R. D. Gaz, W. C. Faquin and M. J. Ott, "The Effect of Surgery and Radiotherapy on Outcome of Anaplastic Thyroid Carcinoma," Annals of Surgical Oncology, Vol. 9, No. 1, 2002, pp. 57-64. doi:10.1245/aso.2002.9.1.57

[58] N. Besic, M. Hocevar, J. Zgajnar, A. Pogacnik, S. GrazioFrkovic and M. Auersperg, "Prognostic Factors in Anaplastic Carcinoma of the Thyroid-A Multivariate Survival Analysis of 188 Patients," Langenbecks Archives of Surgery, Vol. 390, No. 3, 2005, pp. 203-208. doi:10.1007/s00423-004-0524-5

[59] T. Kobayashi, H. Asakawa, K. Umeshita, T. Takeda, H. Maruyama, F. Matsuzuka and M. Monden, "Treatment of 37 Patients with Anaplastic Carcinoma of the Thyroid," Head \& Neck, Vol. 18, No. 1, 1996, pp. 36-41. doi:10.1002/(SICI)1097-0347(199601/02)18:1<36::AIDHED5>3.0.CO;2-\# 